\title{
Estimation of the state of the road industry of Voronezh: ways of modernization and modern methods of its development
}

\author{
Alla Polovinkina ${ }^{1}$, Tatyana Sviridova ${ }^{1, *}$, Irina Kuleshova ${ }^{1}$ \\ ${ }^{1}$ Voronezh State Technical University, Moscow Avenue, 14, Voronezh, 394026, Russia
}

\begin{abstract}
The paper is dedicated to the estimation of the state of the road economy of Voronezh up to date. The state of the Voronezh road system is analysed, statistical data are given, and the problems of the city transport system are studied. On the basis of all the data obtained, ways to solve existing problems are proposed and long-range programs for the construction of new and reconstruction in operation roads are considered. The complex of works of the improvement state of the road system planned for the near future is described in detail.
\end{abstract}

\section{Introduction}

One of the most important factor characterizing the growth of the region's economic development is the condition of roads. According to the data of the regional office of the Federal Service for Government statistics for the Voronezh region, the length of the paved roads of the urban district of the Voronezh (including non-public roads) is increased every year. The dynamics of the increase is shown in the Figure 1.

The fact is a large part of roads has a high degree of wear and heavy workload. A strong influence on the road situation is exerted a by the growth of the population, growth of the population provokes an increase in the traffic intensity, is which leads to a decrease in the quality of roads, long traffic jam and an increase in the level of accidents [1].

Therefore, great road funds have been begun forming since 2012. The changed approach by the Federation to financing the modernization of road industry has allowed paying more of attention to roads. In addition, most importantly, it has allowed predicting the near future and further steps to improve them.

\footnotetext{
*Corresponding author: cviridova81@mail.ru
} 


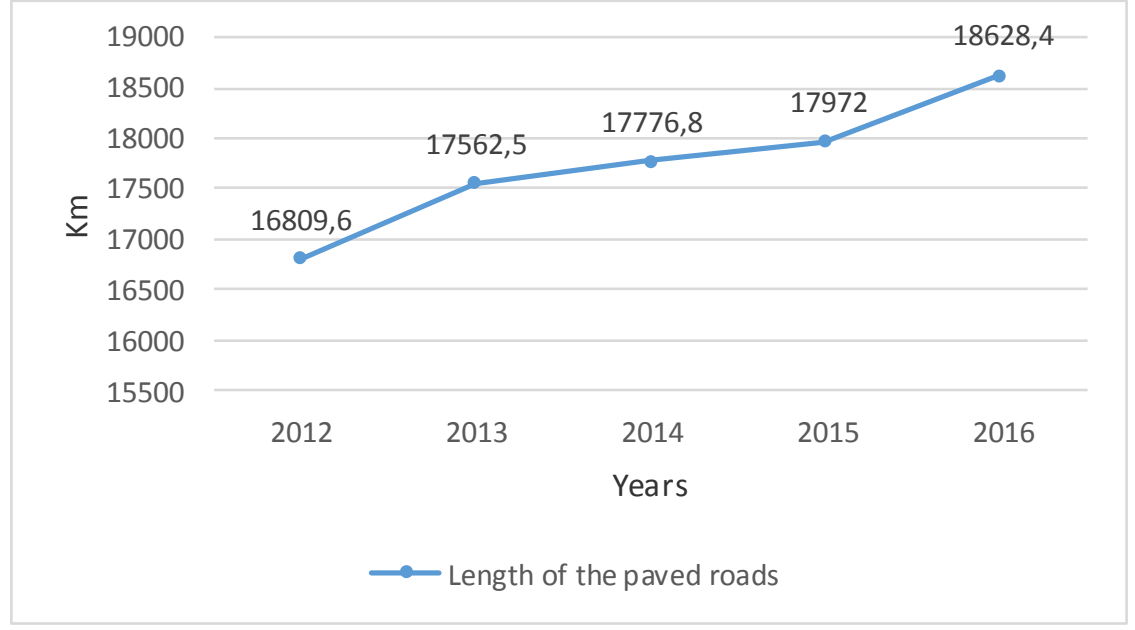

Fig. 1. Dynamics of increase of the lengths paved roads in Voronezh.

\section{Materials and methods}

So in 2017 in Voronezh the priority national project «Safe and qualitative roads» has started, is directed purposing the following goals: [2]:

- bringing in the normative state of the road system of urban agglomerations (in 2018 year $-50 \%$, in 2025 year $-85 \%$ );

- reducing of the number of traffic accidents on the road system of urban agglomerations (in 2018 year - by $50 \%$ of 2016 , in 2025 year - by $85 \%$ );

- optimization of traffic flows, ensuring the synchronization of the development of all type's vehicle of urban agglomerations, passing on transportation of cargo to other kinds of transport, passenger transport to public vehicle;

- ensuring of increase in the efficiency's application of road funds due to the creation of automated monitoring systems, directed at interacting with road users.

Due to the beginning of the implementation of this project in 2017 year, Voronezh has already seriously updated its road network. The contractors built $31.2 \mathrm{~km}$ of new roads, completed the construction of the eastern bypass of the urban-type settlement Podgorensky and reconstructed the bridge over the river Svinuha in the Rossoshansky district. Also, road workers have begun reconstruction of the of Voronezh-Lugansk highway in the Khokholsky and Ostrogozhsky districts and the M4 Don road in the Liskinsky district. There was the total length of the renovated roads $576 \mathrm{~km}$, of which $156.7 \mathrm{~km}$ are the streets of the regional center [3].

On the successful steps taken to improve the state of the road industry is shown by the increase of the city's position by 12 lines (from 80 to 68) in the rating of the quality's the roads of Russia for 2017 year, it based on the research of the social movement for the development of the transport system is Killed Roads [4].

And in 2018 in Voronezh as part of the project of the «Safe and qualitative roads», about 100 road objects with a total length of more than $150 \mathrm{~km}$ are planned to be put into operation, the main of which are Moskovsky Prospekt, Kol'covskaya, Plekhanovskaya and others.

This was reported by the head of the department Maxim Os'kin following the results of the meeting in the road department of the region. In addition, He added that as part of the project road works are planned in the adjacent areas to Voronezh. This are such areas as: 
Panino - Verkhnyaya Khava - Malaya Privalovka; Kursk - Borisoglebsk - Khokholsky Rep'yevka; Voronezh - Maslovka - dam of reservoir and others. The total number of urban roads in regulatory state, should grow to almost $61 \%$ [4].

It is worth noting that the size of the Voronezh region road fund for 2018 year is 8.96 billion roubles, which is 2.31 billion roubles less than funds was allocated for repair of roads in 2017 year (11.27 billion roubles). Such event can cause difficulties.

In addition, Voronezh is fulfilling the municipal program «Development of the transport system», the action of which is designed for 2014-2020. On March 24, 2017, the Voronezh administration made changes to the corresponding program, which are directed to enhance the integrated security and stability of the megacity transport system [5].

The total amount of the program funding is 19 billion 25 million roubles. As a result of its fulfilment in Voronezh, the length of public roads accord with regulatory requirements should be $762 \mathrm{~km}$. Reconstruction of 2 road interchange, construction (reconstruction) and repair (complete replacement worn out surface course over $1 \mathrm{~km}$ ) $207 \mathrm{~km}$ of public roads, will be carried out. During 3 years, 1068 units of city public vehicle will be purchased, and $87.5 \%$ of the transport used for passenger transportation will be equipped with the GLONASS system (Global Navigation Satellite System). Building 33 traffic lights and installing 6013 road signs is also planned [5].

Based on the interview with the head of management of road industry of city hall's the Voronezh is Oleg Kotov, it seems that for the near future, a set of works has been planned to improve the state of roads. Besides this two large-scale transport projects are planned, is which will be carried out in three stages [6].

The first stage is planned to be completed by 2020 year- is an expansion of the streets of the 60th Army, Solnechnaya and Svoboda it is which will be let carrying out into practice duplicate of the Moskovsky prospect. Also, the reconstruction of the road along Tsiolkovsky from Heroes Stratosphere Street to Ilyushin will be realized, is which will be reduced the traffic flow on Dimitrova. In addition, construction of large road interchange at the intersection of Leninsky Prospekt and Ostuzheva Street is planned, the project of which has been developed back in 2013 (Figure 2).

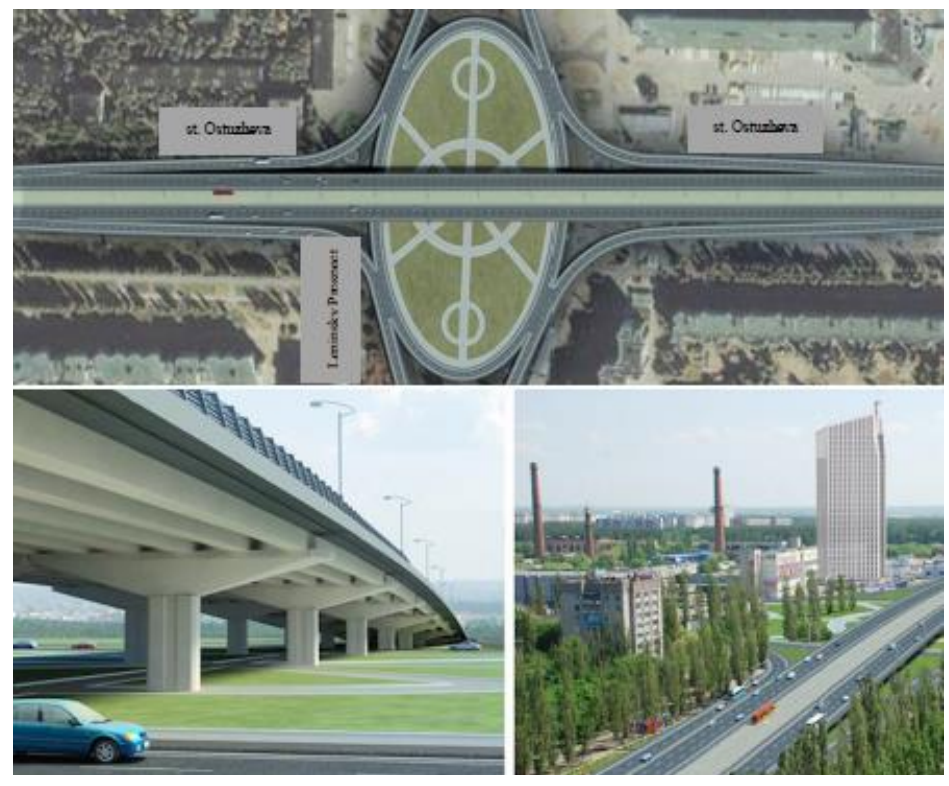

Fig. 2. The project of the road interchange at the intersection of Leninsky Prospect and Street Ostuzheva. 
The second stage involves the construction of the so-called right-bank ring, and it includes the creation of a four-lane road interchange from the streets of AntonovaOvseenko through Moskovsky Prospekt to Lomonosova (Figure 3). Then the road will continue to the North Bridge along the embankment's Maxim Gorky. At this stage, the plans also include the construction of a highway from the Ostrogozhskaya to Vogresovsky Bridge and highway from the intersection of Heroes Sibiriakova and Prospect Patriots to Ostrogozhskaya. The works are planned to be completed by 2023 [6].

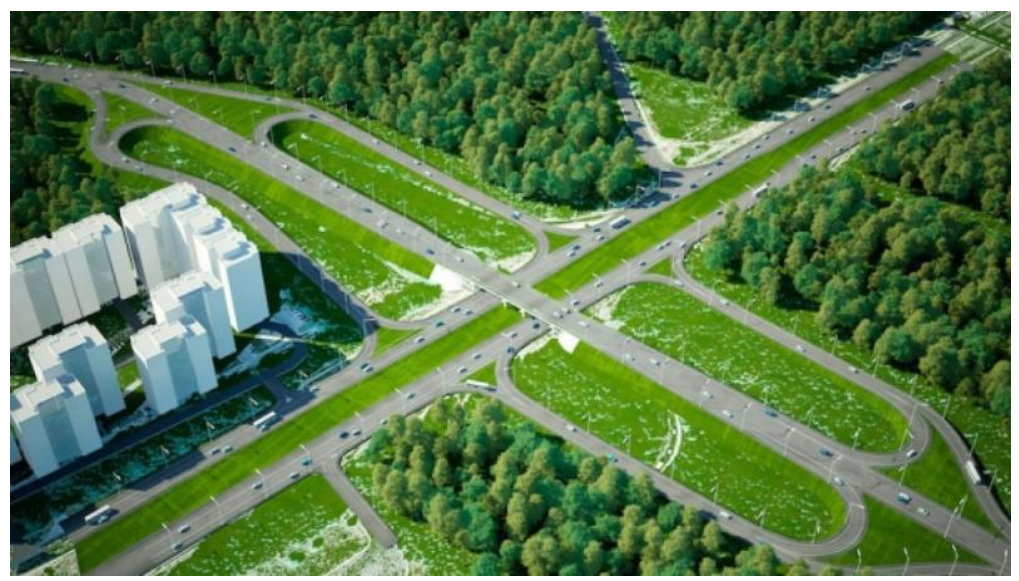

Fig. 3. The project of the road interchange at the intersection of Antonova-Ovseyenko and Moskovsky Prospekt.

At the third stage, the fulfilment of which is set out only after 10 years, the authorities will plan to build a large automobile ring around Voronezh. To the project will be fulfilled the so-called Southern Bridge must be erected at the Voronezh Reservoir - from Ostrogozhskaya to the road interchange on Novosibirsk Street, Oleg Kotov noted. Panfilova, Kuibysheva, Kaliningradskaya and Planetnaya streets are supposed to be expanded to a four-lane highway to the existing road interchange at the intersection with the M-4 Don.

Besides, to the discrepancy of the quality of roads to the requirements, there are serious problems in the sphere of city public vehicle of Voronezh. Public vehicle of Voronezh not only it does not become an attractive alternative to a personal vehicle, but it also does not carry out the basic function of maintaining the transport unity of the urban district. The technical condition and comfort level of city public vehicle mostly do not meet modern requirements. Therefore, the development of the transport system of the urban district of Voronezh is becoming a necessary condition for the fulfilment of the strategic plan of the social and economic development of the urban district of the of Voronezh [7].

In recent years the central streets are said by many designers of projects for improve the state of the transport system of Voronezh have been exhausted their traffic capacity and the construction of new roads and interchanges will not help to make away with traffic jam. Therefore, the right decision, by their opinion, is the construction of an underground on the city's territory, which will take over to $60 \%$ of passenger traffic [7].

So recently, the Voronezh construction company Kinosarg announced a road map for fulfilment project of construction the Voronezh underground, a feasibility study and construction documents. According to the proposed project, this Voronezh underground is supposed to be consist of three intersecting branches [7]:

- green line is Moskovsko-Aviazavodskaya;

- red line is Tambovsko-Kurskaya; 
- blue branch - Rostovsko-Semilukskaya.

Total length of lines will be $58.6 \mathrm{~km}$.

A detailed diagram of the planned location of the lines is shown in the Figure 4.

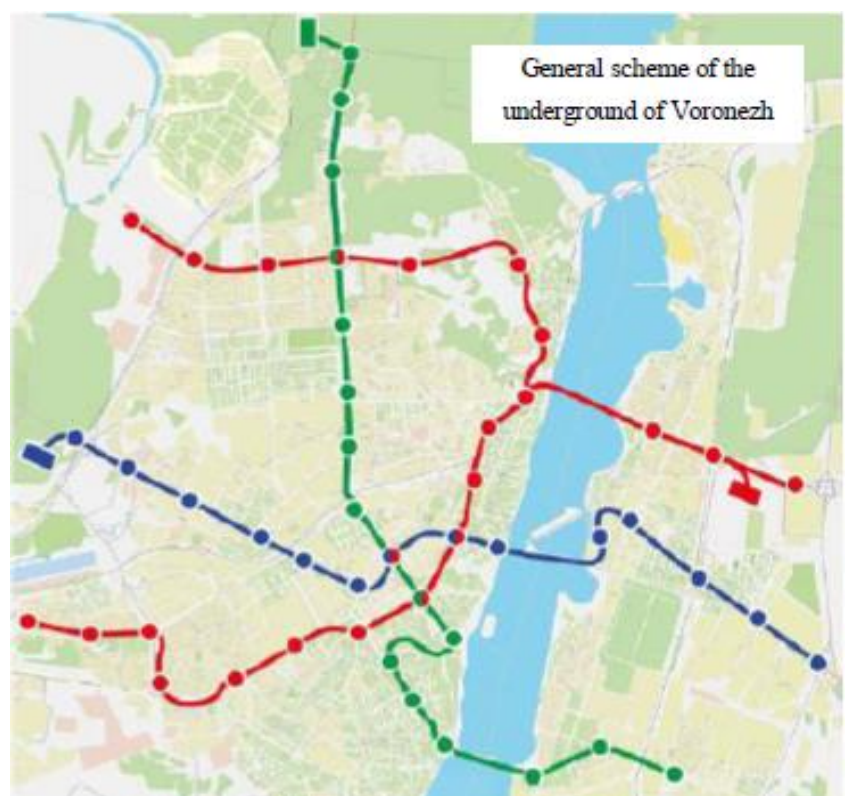

Fig. 4. Diagram of the location of the lines' the underground.

\section{Results}

Based on the above due to the start of the fulfilment of the priority national project «Safe and qualitative roads», which was recently started, in $2017,157 \mathrm{~km}$ of roads were repaired including the main highways that were critically in need of repair. In 2018, the fulfilment of this project will be continued. In the main the repair works are supposed to be carried out

As regards the way forward, if the two large-scale transport projects described above are succeed fulfilling, this will a lot increase the level of road infrastructure in Voronezh and will solve a great part of number of present problems. As a rule, the such development of the industry is certain to be brought into the difficulties that need to be overcome. First of all, they are associated with minimizing the inconvenience of citizens during the repair work.

As for the construction of an underground in the territory of Voronezh, this is certain to arouse special interest among city residents, economists and public Figures. However, the authorities have not yet taken to predict the terms of construction, as long as one of the key problems in the build of facilities of this scale is their extremely high cost and the complexity of finding sources of financing. If such modernization takes place in the future, it will radically help solve problems to traffic jams, improve the quality of city public transport and give great convenience to citizens.

\section{Conclusions}

Thus, a lot of measures is obviously by authorities to take improving the state of the road industry of the city. Many ideas have been proposed and in present time, there is a constant search for funding for their fulfilment. While some of ideas have already been approved 
and their fulfilment is planned in the near future. If by 2023 two large-scale projects such as the construction of an underground and the reconstruction of the road system are succeeded realizing, the transport «life» in the city is really to be become more comfortable, and the road industry of Voronezh will rise to a new level.

\section{References}

1. I. Solov'eva, V. Pisarevskaya, Questions of statistics 9, 49-54 (2013)

2. V. Kankhva, MATEC Web of Conferences 106, 08027 (2017) doi.org/10.1051/matecconf/201710608027

3. V. Kankhva, MATEC Web of Conferences 106, 08022 (2017) doi.org/10.1051/matecconf/201710608022

4. V. Kankhva, E3S Web of Conferences, 33 (2018) doi.org/10.1051/e3sconf/20183301036

5. E. Nezhnikova, Procedia Engineering, 165 doi.org/10.1016/j.proeng.2016.11.854

6. E. Nezhnikova, IOP Conf. Series: Earth and Env. Sc. 90, 012161 (2017) doi:10.1088/1755-1315/90/1/012161

7. E. Nezhnikova, O. Papelniuk, A. Gorokhova, International Journal of Energy Economics and Policy 8(1), 203-211 (2018) 